\title{
Understanding Drivers of Crime in East Baltimore: Resident Perceptions of Why Crime Persists
}

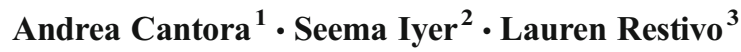

Received: 3 July 2015 / Accepted: 11 November 2015 /

Published online: 25 November 2015

(C) Southern Criminal Justice Association 2015

\begin{abstract}
Urban neighborhoods are frequently associated with high rates of crime, unemployment, poor educational systems, poor housing conditions, and health related problems. Theories of social disorganization, social isolation, and broken windows all explain how and why social problems develop and persist within urban settings. Drawing on these theories, this study examines how residents perceive local community problems in an East Baltimore neighborhood. Eight focus groups were conducted with participants who live and/or work in the area to identify common neighborhood issues. Problems commonly identified were: the presence of physical disorder, issues related to crime and law enforcement, lack of employment opportunities, and limited youth activities. Embedded under many of these themes was the recognition that the neighborhood lacks collective efficacy to fix community problems and maintain social control. Implications for improving neighborhood disadvantage will be discussed.
\end{abstract}

Keywords Urban crime - Disorder C Collective efficacy - Qualitative research · Focus groups

Andrea Cantora

acantora@ubalt.edu

Seema Iyer

siyer@ubalt.edu

Lauren Restivo

lauren.restivo@ubalt.edu

1 School of Criminal Justice, College of Public Affairs, University of Baltimore, 1420 N. Charles Street, Baltimore, MD 21201, USA

2 Baltimore Neighborhood Indicators Alliance, University of Baltimore, 1420 N. Charles Street, Baltimore, MD 21201, USA

3 University of Baltimore, 1420 N. Charles Street, Baltimore, MD 21201, USA 


\section{Introduction}

The crime rate in urban America has been declining significantly since the 1990's, yet in nearly every city, there remain pockets of high crime areas. Many of these neighborhoods have been the subject for implementation of evidence-based crime-reduction interventions, yet no one program can address the underlying causes of neighborhood distress that lies at the root criminal activity. In 2012, an interagency collaborative led by the U.S. Department of Justice began to provide place-based funding through the Byrne Criminal Justice Innovation (BCJI) grant to provide a comprehensive approach to address persistent issues of crime and disorder in urban neighborhoods. Baltimore City was one of the recipients of the grant in order to develop a plan to eliminate crime hotspots in an East Baltimore neighborhood as well as work with residents, and community groups, to understand systemic issues that allow or cause crime to continue in the neighborhood. ${ }^{1}$ The neighborhood was selected in part because of the strength in the local network of community groups to implement strategies to address systemic issues. Although the primary goal of this project is to reduce criminal behavior and conditions that contribute to crime, this grant will also seek to enhance collective efficacy among local residents and organizations. Efforts to reduce crime and improve neighborhood conditions will likely stabilize the neighborhood, thereby increasing collective efficacy. Plans to measure collective efficacy are currently under development. The focus of this article is to present findings from focus groups conducted during the early research stage of the BCJI grant. The focus groups were conducted to gain a deeper understanding into the perspectives of neighborhood residents' and other stakeholders as to why crime persists and what solutions they believe would be most effective in the future.

\section{A Review of Relevant Literature}

\section{Physical and Social Disorder}

The focus of the BCJI grant on improving neighborhood conditions is significant because of a growing literature on the "durability" of certain behaviors, social problems and physical disorderliness at the community level (Sampson, 2012). Urban neighborhoods, particularly those that have experienced rapid population decline, as is the case of East Baltimore, often experience a multitude of social problems in the form of high rates of unemployment, incivilities and disorder, substance abuse, vacant and abandoned houses and lots, have more female headed households, experience lower educational achievement, and have higher health hazards (LeGates, Potepan, Blash, and Gilbert, 1996). As a result, these urban neighborhoods experience high residential turnover, which has longer-term consequences for communities, including destabilizing residential cohesion and neighborliness (Shaw and McKay, 1942; Cullen and Levitt, 1999; Peterson, Krivo, and Harris, 2000). Shaw and McKay (1931) elaborated on the social conditions within urban neighborhoods and emphasized the negative consequences can result in community social disorganization. Specifically, they argue that

\footnotetext{
${ }^{1}$ The authors of this paper were involved as research partners in the development of the plan.
} 
low economic status, residential turnover, and racial homogeneity directly contribute to the incidence of crime and disorder because these conditions result in a less unified and more socially "disorganized" neighborhood. Additionally, Wilson (1987) added that the lack of employment in these areas further contributes to the concentrated disadvantage and resident isolation. Taken together these conditions create an environment that weakens mutual trust between residents, thereby reducing the informal social controls that have the ability to regulate and control crime and deviance.

Prior research has shown that common in socially disorganized neighborhoods are the presence of social and physical incivilities. Physical incivilities are commonly referred to by the presence of graffiti, vandalism, debris, litter, and unkempt yards (Pitner, Yu, and Brown, 2012; Sampson and Raudenbush, 1999, 2004; Taylor, 1999). Social incivilities in contrast, include disruptive neighbors, gangs, drugs, and prostitution activity (Pitner et al., 2012; Sampson and Raudenbush, 1999, 2004). Wilson and Kelling's (1982) broken windows theory emphasized that physical and social incivilities (or disorder) create spaces that attract potential offenders and deviant behavior. It is often the spiral of decay that explains how minor signs of disorder left unaddressed leads to other disorder and eventually crime (Skogan, 1990). Even minor forms of incivilities can create larger, more serious criminal problems as they communicate indifference and lack of care on the community's part (Wilson and Kelling, 1982). Once a community starts having abandoned or unattended property, neighborhood conditions will start to deteriorate. The process of residential turnover, widespread litter, and norms conducive to deviance start to form, which slowly but surely deteriorates the neighborhood.

Many researchers have linked incivilities to the idea of place attachment, such that when citizens feel their homes and neighborhoods are of value, their behaviors align with the goal of ensuring kempt and orderly yards (Brown, Perkins, and Brown, 2003; Pitner et al., 2012). In urban areas with high residential turnover rates people are less likely to invest in beautifying their properties (Brown et al., 2003; Spelman, 1993). As properties are unkempt, and disorder builds up, the negative message being communicated to potential investors and homebuyers may sway their investment decisions (Sampson and Raudenbush, 1999). Deteriorating conditions, particularly abandoned properties, attract crime (Spelman, 1993) and negatively affect property values (Immergluck, 2012), which also may impact the decisions of prospective buyers.

Skogan (1990) found that high levels of neighborhood disorder is also linked with low neighborhood satisfaction, low confidence in neighbors, and enhanced fear of crime. Research on broken windows theory also finds a relationship between physical disorder and quality of life (i.e., happiness and life satisfaction), whereas fewer perceived problems with neighborhood disorder was related to high levels of quality of life (Chappell, Monk-Turner, and Payne, 2011). Several empirical studies on broken windows theory found evidence that enforcement of disorder offenses reduces violent crime (Kelling and Sousa, 2001; Messner et al., 2007), however others have found no effect (Katz, Webb, and Schaefer, 2001).

As asserted by Sampson and Raudenbush (1999), neighborhood disorder can be mediated by social bonding and relationships formed within neighborhoods when geared towards crime control and prevention. Referred to as the collective efficacy ${ }^{2}$ theory,

\footnotetext{
2 The term collective efficacy is defined as the linkage of cohesion and mutual trust with shared expectations for intervening (working together) in support of neighborhood social control (Sampson et al., 1997).
} 
authors emphasize how relationships and friendships can lead to mutual trust and shared expectations that can control for crime and deviance (Sampson, Morenoff, and Earls, 1999). Existing studies that use survey designs to evaluate collective efficacy often ask questions about the prevalence and frequency of neighbor interactions, willingness to intervene when either crime or deviance occurs, and the level of trust and shared values (Browning, Feinberg, and Dietz, 2004; Pitner et al., 2012; Sampson and Raudenbush, 1999; Sampson, Raudenbush, and Earls, 1997).

Traditionally, collective efficacy is based on the idea that communities with strong ties and social cohesion (i.e., high levels of collective efficacy) influence informal social control and lead to lower crime rates (Sampson, 2013). Browning et al. (2004), however, found that strong networks ties may actually hinder efforts to control crime because of the type of networks that exist. For example, in neighborhoods with a strong illicit drug market residents are likely to be related or acquainted with those engaged in this illegal behavior. Residents with these networks may be less likely to exert informal control. Consistent with Browning et al.'s (2004) finding, Sampson (2013) argues that some neighborhoods have strong social norms about not intervening (e.g., the "Do not Snitch" mindset) even in places with strong network ties. Wilson (1996) proposed that strong networks in poverty stricken disadvantaged areas that are socially isolated from informal and formal social controls can act to strengthen and spread norms conducive to deviance.

\section{Barriers to Employment}

There is a long standing theory that legitimate employment enhances social ties to conventional norms, and serves as an informal social control mechanism, therefore preventing crime (Sampson and Laub, 1993). Research also finds that when individuals have stable employment they are less likely to engage in criminal behavior (Visher and Travis, 2003). The quality of employment also plays a role in criminal behavior and social control, whereas higher quality jobs lowers criminal motivation and increases levels of social control (Crutchfield and Pitchford, 1997; Uggen, 1999).

In low-income communities unemployment rates are often high due to the limited job skills of residents, the lack of employment market, and the high number of people with criminal records. The impact of unemployment in low-income neighborhoods has most notably been documented in William Julius Wilson's When Work Disappears (1996). Wilson highlights the high rate of joblessness in urban centers in the early 1990s. He contends that poverty has always existed, but even those who were considered poor were consistently working in low-skilled jobs. This began to change drastically in the 1980s and 90s, and largely impacted poor African American communities. Wilson (1996) described the national decline in low-skilled work due to the decline in manufacturing, globalization and development of technology. As the labor market has changed, and low-skilled jobs moved away from urban centers, access and affordability of transportation became a barrier for low-skilled, poor workers. The combination of low-skills, low-education, and family poverty impacted, and continues to impact, earnings and job access.

Coupled with this reality is the flight of middle-class families from poor communities (Pietila, 2010; and Wilson, 1996), the increase in single-parent households (Wilson, 1996), and the removal of men from these neighborhoods as a result of arrest and sentencing 
policies. A natural consequence is the concentration of poor, unemployed residents, and fewer role models for local children (Wilson, 1996; Clear, 2007).

These challenges are further complicated when people return from incarceration with a criminal record. Considering most returning prisoners are released to urban areas with weak labor markets, and are often in competition with other low-skilled residents, creates even greater employment challenges (Lynch \& Sabol, 2001). For example, in Maryland most released prisoners return to Baltimore City (La Vigne, Kachnowski, Travis, Naser, and Visher, 2003).

Many returning prisoners have poor employment histories and lack the skills necessary for securing work. Visher, Debus-Sherrill, and Yahner (2011) research on former prisoners' experiences finding work after prison found that individuals with little to no work history had poorer job outcomes than individuals with a history of recent and consistent employment. The stigma associated with having a criminal record also complicates the situation (Sampson and Laub, 1993; Solomon, Roman, and Waul, 2001; Western, Kling, and Weiman, 2001). This stigma is known to decrease employer's willingness to hire returning prisoners, resulting in difficulties finding jobs (Pager, 2002; Petersillia, 2001). Research indicates that employers are unwilling to hire people with criminal records because they view them as untrustworthy, a threat to their business, and a potential legal liability (Holzer, Raphael, and Stoll, 2004).

\section{Youth Programs and Mentoring}

Providing structured activities for youth is also important in the prevention of crime and delinquency. Recreation centers are often places where young people can congregate and engage in pro-social structured after-school activities. In the early 1980s over 130 recreational centers existed in the City of Baltimore. By the late 1980s the number of the recreation centers declined with around 60 in operation at the end of the 1990s (Van Arnum, 2014). In 2012 the city closed 20 recreation centers with the intention on investing in a few high-quality centers (Wenger, 2013). As of 2014 there were 40 centers operated by the city, and several more run by schools or private organizations (Van Arnum, 2014).

Providing afterschool programming is most important due to the fact that most juvenile offending, and victimization, occurs during after school hours (Office of Juvenile Justice and Delinquency Prevention, 2014). Youth are often unsupervised during this time which increases their risk of offending and victimization. Structured activities, such as public or privately run programs like the YMCA or community centers, are more likely to reduce delinquent behavior than those that are unstructured (Osgood, Anderson, and Shaffer, 2005; Rorie, Gottfredson, Cross, Wilson, and Connell, 2011). Research also indicates that poorly structured programs at community recreation centers are not effective at reducing delinquency because they attract young people with academic and behavioral problems (Mahoney, Stattin, and Magnusson, 2001).

After-school programs that provide a range of activities from academic, vocational, recreational, and life skills are effective at keeping kids from engaging in delinquent behavior (LaFrance and Twersky, 2001). LaFrance and Twersky reported that youth enrolled in the Bayview Safe Haven Program were rearrested at lower rates than youth not in the program (40\% and $59 \%$ respectively). They also reported that youth who 
voluntarily participated had lower arrest rates than those who were mandated by the court system.

Community mentoring programs are also useful in engaging youth with structured activities. These programs are especially vital in distressed communities that lack role models for young people. The disappearance of men in the community means many young people, particularly boys, do not have strong male role models (Clear, 2007). To fill in this gap many distressed communities develop mentoring programs. For example, Big Brothers Big Sisters targets youth from single-parent households in low-income areas, including youth with incarcerated parents. Mentors in the program engage youth with structured activities for the purpose of developing a supportive trusting relationship. Research on Big Brothers Big Sister mentoring program indicates that youth engaged in this program are less likely to use drug use, engage in assaultive behavior, do better in school, and have stronger relationships with parents (Tierney, Baldwin Grossman, and Resch, 2000).

\section{Police-Citizen Relations}

Another common characteristics of disadvantaged communities is the level of dissatisfaction residents have of law enforcement (Sampson and Bartusch, 1998). Issues of trust, effectiveness, and cooperating with law enforcement have been well documented. Research often finds that citizens with positive views towards law enforcement are more likely to trust the police, report crime, and informally exert social control (Nix, Wolfe, Rojek, and Kaminski, 2015; Ren, Cao, Lovrich, and Gaffney, 2005; Tyler, 2005). Citizens often trust the police when they view their performance as effective in controlling crime, and when they feel that they are treated fairly (Tyler, 2005). In a study that looked specifically at the influence of collective efficacy on levels of trust in police, Nix et al. (2015) found that both procedural justice (i.e., fairness in police procedures) and collective efficacy influence level of trust in police, but procedural justice was a stronger factor. Nix et al. argue that people with lower perceptions of collective efficacy will often perceive police behavior as unfair.

Having negative interactions with law enforcement is also linked to negative attitudes towards them. Carr, Napolitano, and Keating (2007) conducted a study of in-depth interviews with youth in high-crime neighborhoods of Philadelphia to assess their dispositions toward police. They found that having a negative interactions with police was the most common reason young people have negative dispositions toward law enforcement. Viewing police as ineffective was the second most common reason youth viewed police negatively. When describing ineffective policing, youth often viewed their neighborhood as "under-policed" due to observations of poor response times. Youth in this study were also asked about how to reduce crime in disorder. Most discussed improving law enforcement - including increasing the number of police. Youth believed that increasing the number of police in the community, and enforcing existing laws, would make it more difficult for people to commit crime. Youth also discussed the need to enhance youth activities so young people have a positive alternative to the negative community influences. This article presents research conducted in an urban neighborhood of East Baltimore that shares many of the characteristics highlighted in the literature. Focus group data was collected to assess the neighborhood's top perceived problems, the cause of the problems identified, and 
potential solutions to reduce/eliminate the problem. Focus group research is often used when researchers desire to understand the perspectives of local residents, especially when seeking to address neighborhood problems. For example Seal, Nguyen, and Beyer (2014) conducted focus groups with young people living in an urban neighborhood in Milwaukee to capture their narratives about violence exposure and their view on the causes and effects of violence. The focus groups were conducted as part of a needs assessment for the community to develop a youth violence prevention program. Some of the Byrne Criminal Justice (BCJI) sites are also using focus groups to understand neighborhood problems, including Los Angeles, California and Rainier Beach, Washington.

The following sections of this article introduce the neighborhood where the research was conducted. Next, the methodology section describes the focus group protocol, analysis strategy, and provides a participant profile. After the methods section the results are presented, followed by a discussion of policy and program recommendations.

\section{East Baltimore Neighborhood Profile}

As of 2010, 4033 people were living in the East Baltimore neighborhood where the BCJI grant program is operating. From 2000 to 2010, the number of persons living in the neighborhood declined by nearly $10 \%$. Over the same time, there has been a shift in who is living within the neighborhood. The neighborhood continues to be predominantly African American, but the number of African American and white residents has decreased by 5 percentage points and 1.6 percentage points respectively and the number of Hispanic residents has more than doubled increasing by 8.5 percentage points. In 2011, the median household income in the East Baltimore neighborhood was $\$ 35,283$ which was lower than the Baltimore City median at $\$ 40,100$. More than one out of every four families with children live in poverty, and as of 2011, nearly one out of every four (24\%) families in the neighborhood receives TANF benefits. From 2000 to 2011 , the percentage of properties that are owner occupied decreased from $41 \%$ to $23 \%$. With the transition to more renters within the neighborhood, there has been a decrease in the median home sales price. In 2011, there were 63 homes within the neighborhood that were sold with a median sales price of $\$ 17,500$ which was substantially lower than the median home sales price for all properties sold in Baltimore City $(\$ 100,000)$. The percentage of vacant and abandoned properties in the East Baltimore neighborhood was nearly $16 \%$ (citywide average was $8 \%$ ). ${ }^{3}$

Despite these quantitative measures of neighborhood distress, the community has been organized for many years. In 2006, residents completed a neighborhood master plan to guide impending development around the adjacent anchor institution. The plan cursorily addressed issues of crime and safety, particularly along commercial corridors, with broad discussion on improved quality of life and better sanitation. Residents voiced a need for clean streets and a neighborhood free of crime and violence. The plan recommended addressing crime and safety within the community by developing a multi-prong, multi-year anti-crime initiative, which is one of the reasons that the city decided the BCJI grant would be targeted to this neighborhood.

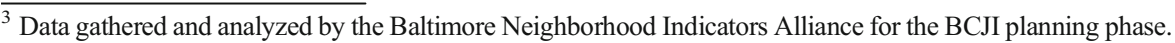


The neighborhood has also been the focus of evidence-based programs to address high rates of crime, most recently with the Baltimore Safe Streets program which aimed at addressing high rates of homicides and non-fatal shootings. Between 2007 and 2008, a program evaluation found that during the first 22 months of the program, the neighborhood did not experience a single homicide, but the number of non-fatal shootings did not decline (Webster, Mendel Whitehill, Vernick, and Parker, 2012). Analysis of crime data for the BCJI grant showed that by 2011, the homicide rate was back up but not to pre-program levels. While the overall violent crime rate was down in the neighborhood specific crimes such as burglaries increased by $45 \%$ between 2000 and 2012. It should also be noted that during 2013, when data was being collected for the BCJI grant, the homicides in Baltimore (including the East Baltimore neighborhood) were up $7 \%$ since 2012 (Daily Beast, 2014). While the Safe Streets intervention continues to operate in the neighborhood homicides and non-fatal shootings continue to occur.

\section{Methodology}

In order to understand residential perception of concerns in the neighborhood, eight focus groups were conducted between July 1st and October 1st 2013. Each focus group began with a brief overview of the Byrne Criminal Justice Innovation (BCJI) Program awarded to the Baltimore City Mayor's Office on Criminal Justice. Participants were informed that the information gathered from the focus group would be used to help develop strategies or programming for the community. After the purpose of the focus group was explained participants were briefed on the informed consent process and ensured that confidentiality would be protected. Participants were also asked to fill out a short survey on their perceptions of the top three neighborhood problems, the cause of each problem, and a potential solution to reduce/eliminate the problem. During the focus group each participant had the opportunity to discuss their responses. Collectively, participants discussed a range of ongoing problems within the neighborhood. Each focus group conducted lasted approximately two hours. Although participants were not compensated for their participation light refreshments were provided. ${ }^{4}$

\section{Participants}

A total of 40 residents, employees, and stakeholders ${ }^{5}$ participated in 8 focus groups between July 1 st and October 1 st 2013 . The 40 participants included 24 residents, 4 employees who work but do not live in the area, and 12 stakeholders who work at various non-profits, or faith-based groups in the neighborhood. The majority of stakeholders also live in the neighborhood. Participant ages ranged from 18 to 70 years old. The majority of participants $(80 \%)$ were African American. The first two focus groups consisted of residents active in the neighborhood. They signed up for the focus

\footnotetext{
${ }^{4}$ Refreshments were not purchased with federal funding. The researchers used their own money to purchase water and refreshments.

${ }^{5}$ Stakeholders included members of the BCJI steering committee, workers from local non-profits and faith-based programs.
} 
group while attending a neighborhood meeting. Business owners and workers from the neighborhood were recruited through a local merchants association for the third focus group. The forth focus group targeted residents from the southeastern part of the neighborhood. Researchers were informed by stakeholders that residents living in the southeastern section of the neighborhood are not as engaged in the community, and do not attend neighborhood meetings or events. Therefore, to reach these residents flyers were distributed door-to-door. Additional efforts to recruit this population involved informing residents as they walked past the library before the focus group began.

The fifth and seventh focus groups specifically targeted young residents. Two local neighborhood programs volunteered to host and recruit participants for these groups. Both groups consisted of young people between the ages of 18 and 30, as well as youth workers. The 6 th focus group included community stakeholders and members of a coalition overseeing the grant. All members of the Coalition were invited to participate and were informed via email invitation. Lastly, with consideration for the growing Latino population in the neighborhood, efforts to recruit Latino residents were implemented, however only one resident participated.

\section{Data Preparation and Analysis}

During each focus group detailed notes were typed on a laptop by a research assistant. As much as possible responses were recorded verbatim. Eight transcripts were produced resulting in a total of 115 pages with 31,431 words. Each transcript was stripped of any identifying information and imported into ATLAS.ti, a qualitative software program. ATLAS.ti was used during the initial coding phase. Initial coding involves reviewing each transcript, highlighting segments of text, and applying a short one to three word code to represent the meaning of text. Over the course of coding each transcript, common codes were developed and applied to additional transcripts (e.g., "lack of employment" becomes a common code once it is identified multiple times). Codes were grouped into two categories: neighborhood problems and potential solutions. The aim of the analysis was to find themes common among all focus group transcripts.

\section{Results}

Consistent with the literature on urban crime problems, residents discussed multiple neighborhood problems during the focus group sessions. The most common problems identified by residents were 1) physical disorder, 2) lack of employment opportunities, 3 ) lack of youth programs, and 4) crime and law enforcement response. The following section describes these themes and potential solutions identified by residents.

\section{Physical Disorder}

Many issues related to physical incivilities were discussed. The physical appearance of the neighborhood was linked to safety and crime issues, frustration over the lack of resident and property owner accountability, and the negative message sent to local 
residents and outsiders. Participants also identified the lack of resident involvement to correct some of the deteriorating conditions within the neighborhood. The core problem identified by participants was the ongoing sanitation issues in the neighborhood. They described the constant buildup of trash, illegal dumping in alleys and near vacant buildings and lots, and littering because trash cans are too full or not available on certain blocks. According to residents, the constant trash left unattended attracts bugs, rats, and more littering. Many residents described a neighborhood that is dirty and unkempt. Often, residents linked the sanitation issues with the presence of vacant buildings. "Well, the abandoned property, the way I see it, I feel like it brings more trash, by nobody having lived there for so long, they get a stench and the neighborhood starts to smell, the rodents get a free place to live and they start to move into places with kids."

Most participants felt like neighbors on their block and around the neighborhood litter, dump their garbage, and simply do not care. One resident, however, believes people do care but the lack of resources contributes to the problem. "There are a limited number of trash cans. People want to throw out trash. People stuff things in the trashcans till they are overfilled."

Another resident described her problem with trash and rats. She often calls $311^{6}$ to report trash and rat problems. Regardless of her multiple attempts to keep her property and street clean no one else on the block helps to keep it clean. On one occasion she was told to request a dumpster. "I cannot be the only one requesting a dumpster. I need other neighbors to help. I need neighborhood leaders to come walk with me and get some help, my kids deserve better than this." This frustration was expressed by many participants who take care of their property and do not contribute to the sanitation issues. Participants discussed the lack of accountability on behalf of residents who fail to upkeep their property and ignore the trash and deterioration of the block. Participants talked about the lack of property owner accountability - including the City government. Many vacant residential properties in the neighborhood are owned by individuals, private companies, or the City. Participants identified these vacant properties, in addition to rental properties, as part of the deterioration of the neighborhood. Property owners were said to be "absent" and fail to fix damaged property. Participants expressed great frustration over the consistent damage and trash piles. The following quote is from an African American female resident in her $50 \mathrm{~s}$.

"Most of the problems we have are from rental properties, we should have landlords held accountable maybe they need to be educated. They should go to a class and check on the property and come out and see what's going out. The property owners are more concerned in getting that money, section 8 , but they don't care they don't wash the steps and clean their front yard. The landlords need to help and be more accountable." (Female resident - focus group 1)

In addition to trash and damaged property, participants felt that the City does not take care of reported sanitation issues. There was also discussion about sanitation

\footnotetext{
${ }^{6} 311$ is a non-emergency service request system. Residents can use this system to report problems with street lighting, trash, potholes, etc.
} 
workers not properly picking up trash or ignoring pickups on certain streets. The following quote is from a 40-year-old African American man who owns a store in the neighborhood.

"Trash pickup is on Thursday mornings and Friday mornings so a lot of merchants throw their garbage where the residents are putting their trash. The trash breeds rodents and bugs, I have personally called 311 at least 12 times for us to get our trash picked up properly. They keep not picking up trash properly. It leaves a big mess on the community." (Male employee - focus group 3)

Consistent with broken windows theory (Wilson and Kelling, 1982), participants discussed the negative message the physical appearance of the neighborhood sends to outsiders. "The root issue is yes cleanness but it's more of what it communicates to people. There is a core group that may care but it's against the majority of people that do not care. How can we fight against that?" Participants described unattractive and unsafe streets that look uninviting, declining property values, and the lack of business owners willing to invest in the area due to physical incivilities and safety issues.

"We need to make these areas more attractive, make it a mixed community, money or not, people want a safe and clean area, access to transportation. There are pluses to these areas but it needs to be attractive, safe and clean. People shouldn't have to worry about the bubonic plaque coming into their houses. If it's clean and safe I think it would be wonderful areas to be in but getting over these bumps is hard. What are the ways that we can set the tone, climate? We need basics. Where I grew up [names different state] when things went wrong people would say something."(African American female resident - focus group 1)

According to participants, the poor housing conditions in the neighborhood create safety issues.

"And the dilapidated houses where people can hide anywhere and our kids cannot be safe...that's a problem and elderly people are scared. You have people running drugs, and nothing is safe. You have poor lighting that adds to the crime and you have abandoned houses and you have people that can't get rid of debris." (African American female resident and worker - focus group 2)

Participants were asked about potential solutions to improving the physical condition of the neighborhood. There was a general recognition that collective action is required to maintain clean and safe streets. There are people in the neighborhood who care and try to improve the physical living conditions of their block, but to residents who see these efforts or are involved in these efforts it is not enough to bring about massive change. "Yeah, I see in the morning people cleaning, picking up trash and other people watching kids outside, I see the effort but I do not think it's enough." Participants were able to identify people in the neighborhood who try to make a difference. "Some neighbors take the trash and clean it up and go into alleys and clean." Another participant stated, "It's the volunteers, my Grandma used to do it." The 
sentiment that a few residents will not make a difference was consistently brought up. A young African American male resident stated:

"Some neighborhoods I lived in, people would put trash cans out and I respect that and some people will get up early and clean their property and their neighbors too, but it's about keeping it clean. It's about getting everyone together, it would progress things more and get better. If people had an incentive, if people knew keeping it clean would be better for the community as a whole, that being clean would open the neighborhood to better things, people would do it. If people have an incentive, keep it clean and the government or community will throw us a block party or something." (Male resident - focus group 4)

This resident continued to explain that over time residents would not need an incentive to keep the neighborhood clean. "If we do that [provide incentive] once or twice or three times and people will see that the neighborhood is clean, people will see that change and respect that and I think it would be a good program."

\section{Lack of Employment}

One of the major problems identified by residents and stakeholders is the lack of employment opportunities for residents. The lack of available blue-collar jobs in the local area and surrounding Baltimore neighborhoods create an overall challenge for residents. Residents do not see new businesses investing in the area which limits the job availability and further creates feelings of hopelessness and despair. The jobs that are available are often difficult for a percentage of residents with criminal records. The stigma and legal barriers to finding work for those with criminal records pushes these residents to continue to engage in illegal work. The consistent rejection from seeking legal work leads to feelings of hopelessness and loss of pride. Consistent with the literature (Solomon et al., 2001; Western et al., 2001; Pager, 2002) issue of criminal records and failure to find legal work was a prominent theme in most of the focus groups.

Residents also spoke about the false promise of local job training programs. Residents - especially those with criminal records - have participated in job training programs but were not placed in a job after completing the training. This experience has left residents discouraged and weary of other job training programs. This further creates distrust and hopelessness. A Caucasian female stakeholder stated:

"The high rate of employment, I think that is a big driving force to crime, it leads to a lot of folks hanging out on corners and it acts as a barrier to employment. This is part of the larger trend but I think it has hit this area pretty hard. We have tried to do things in the neighborhood such as projects with [names local institution], but we haven't been able to get a large-scale solution. There are a lot of training opportunities but there isn't always a job guaranteed at the end of the line, so people are hesitant to do them. So they think why is this time around going to be any different?" (Female stakeholder - focus group 7)

Maintaining employment for the reentry population must be coupled with other social services to address mental health, family issues, poverty, etc. Many residents 
discussed solutions that involve hiring people with criminal records, and young people, to improve the physical conditions in the neighborhood. Combining these three issues (unemployment, lack of youth opportunities, and physical conditions) would address multiple neighborhood problems. Residents also discussed the desire to have more employment focused programs, especially those that teach entrepreneurial skills. A 50-year-old African American male who works and lives in the neighborhood stated.

“These people don't actually get a job once they get done the training. There isn't a money stream in this community for entrepreneurs where people can develop businesses, I have met a lot of young men in this community that have a creative mind but it won't ever flourish in this community." (Male resident - focus group 6)

Residents described a neighborhood of people with creative minds and a desire to be successful. What is missing is the means and support to be successful. Not having the right resources, guidance, and positive mentorship are reasons residents fail to achieve success.

\section{Lack of Youth Opportunities and Mentorship}

Youth are an important component of the East Baltimore neighborhood. Many residents expressed the importance of involving young people in neighborhood improvement efforts. However there is a lack of positive role models, youth programs, and recreational activities to keep kids on a positive pathway. Participants spoke about the issues of youth poverty as a reason for engaging in illegitimate activities due to the need to take care of oneself and family. The negative influences in the neighborhood (e.g., gang and drug activity) further influences young people to pursue criminal pathways.

Some residents expressed fear of young people, or avoidance behavior because they want to shield their own children from negative language and behavior. Some longtime residents spoke about having the authority to walk right up to young people and confront negative behavior on the block. Some of these longtime residents have credibility and authority that young people respect. Regardless of a few elders diffusing negative behavior, the overall lack of youth programs creates an environment where teens hang out on street corners intimidating residents of the community.

"It's not the younger kids, it's the high school kids. At the beginning of the summer, we used to sit on our steps we don't do that anymore. Teenagers all come and gather right on the block and the things they say out their mouths, we don't sit on our steps anymore." (African American male resident - focus group 2)

According to older residents, youth in the neighborhood are not accountable for negative behavior. Older residents discussed how things use to be when they were children living in the community. These residents spoke about historical changes that occurred in many urban centers across the country. They attribute the negative youth behavior to the drug market demand, demise of the family structure, and single parent homes with addicted mothers or mothers unable to supervise children due to multiple 
work demands. In addition to historical changes, employment issues for young people are also prevalent, especially youth with criminal records.

“They feel like they can't get a job, once they get those charges they don't hire them, I have talked to these guys and then they sell the drugs because they can't find a job, for offenders they need it. Once they get a felony, that's it, they can't get a job." (African American female resident - focus group 1)

This resident continued to say,

“They are live rodents. They can't get a job because of their records. We will do the sanitary thing, let them do it. The majority of them are smart and sharp, they don't forget about things. They go to other things but in the meantime, my son is an artist, they draw a mural and people will them, tell others what they do. They tell each other. We have enough abandoned houses, give the kids a job, they are intelligent and these kids are smart but they are easily discouraged. How do you think they kids feel they are pumped up and excited but then they run the record and then that's it. It's let down for these kids. You can deal with the sanitary and the vacancies, but I live in the hood, we need these kids. If I get out of the hood and leave, who is going be the spokesperson? The meat of it is giving the kids a 2 and 3rd chance. People need a second chance, they kids are discouraged. I mentored these kids and I told them they could do it. That's what they need."

According to participants (both young and older), many young people in the community do not have access to resources, are unable to navigate through city systems to get help, or simply do not trust the entities in the community that offer help. Many young people are dealing with adult issues at a very young age. Participants feel that there needs to be life skills training either in the schools or at a local community center. The lack of trust in authority was a strong theme expressed during the two youth focus groups. As participants explained, many youth workers and teachers who work in the community are not from the area and do not share the same life experiences. While these workers are helpful and good intentioned they do not have a strong impact on young people the way a local role model would. Residents want locals to remain and work in the community instead of leaving once they gain success. A question arose about how to keep people from the community in the community. No one had the answer.

Residents of all age groups discussed solutions to unsupervised youth including creating a recreation center. One participant recommended opening up the schools in the neighborhood after hours for youth in the community. It was suggested that this space can be used for constructive programming during the summer time and afterschool when youth are most susceptible to loitering and deviance. After a resident suggested this strategy another resident expressed concern of this not being effective.

\section{Crime \& Law Enforcement Response}

Crime was mentioned during larger discussions about physical incivilities in the area. Residents also linked the crime to lack of employment opportunities, youth activities, 
and the absence of positive role models. Residents also spoke about fear of being a victim of crime, especially during evening hours. Participants were well aware of the drug activity in the neighborhood and specifically discussed the community's main street as problematic for drugs and crime. Some participants recognized the reality of the drug economy as a means to make a living. Although not everyone approves of it, they do recognize why people are attracted to it and the negative outcome that would result by eradicating it.

"I have friends that sell drugs, that's how they afford their bills, their presents for birthday parties. The drug economy is a large part of what is part of the economy here in general and there is no solution for it. If you stop the flow of drugs and the money, what do you think would happen to this neighborhood? It would erupt into violence. It's like an all or nothing strategy, you need to have something to replace the drug economy. There needs to be zero tolerance in drugs." (African American male resident - focus group 7)

The lack of legitimate opportunities and the visible presence of the drug market entices residents, especially youth, to engage in the illegal market. Participants were adamant about the inability to stop drug and other crime in the neighborhood and the necessity to expand legitimate opportunities. Two individuals formerly involved in the illegitimate market stated: "You cannot stop the crime here, we cannot just focus on crime, you cannot stop it but if you give them a way out..." Another stated: "That's not the driving force [crime], the driving force is the lack of opportunity." These responses are similar to Pattillo's (1998) research on neighborhood gang networks. Instead of eliminating the criminal activity, residents either accept it or seek to find alternative solutions to address the root cause (e.g., employment).

Participants also mentioned the presence of large groups of young people loitering in front of the businesses. Some participants described feeling intimidated and avoiding groups of teens. Others described efforts to remove them by calling the police or addressing the issue themselves.

"There are about 15 [kids] of them, they hang out in front of the market, and in the back alley, you pay one guy and then you walk around the alley and pick up your drugs, its hot out people will stand in front of stores or go in stores. They even tried to come into my store but I kicked them out." (African American store owner - focus group 3)

Residents who have called the police explained that police response is not an effective solution and only displaces the youth temporarily. "They move from one corner to the other. When I was growing up, we could not stand on the corner we would get locked up for loitering. Today, these kids do not have consequences." (African American male resident - focus group 2).

The area of the neighborhood that has the most visible drug activity is an area that has the most police presence including security cameras and private security officers employed by a local institution. A 25 year-old African American male participant, who works in the neighborhood, found it ironic that the area has the most surveillance yet the most criminal activity, "What's silly is that they have the most cameras but the most 
crimes." Participants also mentioned the lack of street lighting and abandoned houses on many blocks in the neighborhood.

"And safety, there is too many darkness streets. It's hot in the house and we come outside to get cool and we can't be safe and this dilapidated houses we people can hide anywhere were our kids cannot be safe...that's a problem and elderly people are scared. You have people running drugs, and nothing is safe. You have poor lighting that adds to the crime and you have abandoned houses and you have people that can't get rid of debris." (African American female resident - focus group 2)

Residents had a lot to say about the involvement of police in response to local crime and disorder. Similar to other research (Carr et al., 2007) resident's perceptions of the police have been shaped by their personal experience or observation of resident-police interactions. Overall, residents struggle to trust law enforcement as illustrated though hesitancy to call and report problems, have experienced slow response time or lack of response to calls for service, or over-response to minor problems.

Consistent with the literature (Carr et al., 2007) many residents identified slow police response as an indicator that police do not care. There is "no sense of urgency" when police are called implying that it takes officers a long time to respond to an incident. When police do respond to crime participants described an "over-response" especially during minor incidents. Participants see too many officers at the scene and they take their time before moving on.

"There is no sense of urgency, because I know this for a fact, I have them [police] in my store. We called the police one time where a man tried to go behind the counter and get an [indiscernible]. We held them in the chair until the police came here. We don't play that. But the police didn't want to move on quickly to respond to other calls." (African American store owner - focus group 3)

When residents discussed the "over-response" to certain situations they described the impact the over-response has on the individual and community.

"What I tend to see is disheartening. It takes 6 police officers to take a man down, you have one person sitting there with 6 cop cars. It's embarrassing and it makes it hard for that young person to not get stigmatized or labeled when they come back to the community, it's a waste of time and taxpayers money too." (African American female stakeholder - focus group 5)

On many occasions residents have observed officers not leaving there vehicle when driving by areas with criminal activity. This sends a message to residents not to call the police and report neighborhood problems because they simply do not care. Residents of all ages also discussed fear of calling in criminal activity to the police. Residents who in the past called police complained about poor response time, lack of solving problems, and this leads to not calling in the future. Other residents complained about the anonymous call-in system where residents can report crime by giving an identification number instead of their name. Residents described this system as inefficient and even discussed incidents when police would arrive at the caller's home after the anonymous 
call was made. One resident, fearful of getting involved with law enforcement, described feeling angry after a resident told the police she was a neighborhood leader. Due to her fear she avoids neighborhood leadership roles and simply wants the physical signs of disorder on the block to be addressed.

"It makes me fearful to get involved, I don't want to snitch but to be honest that is what I feel. I have 3 children and when people go home to their cushy neighborhoods without police I have to go home to this neighborhood. People will assume I am snitching. I saw the police one day and my neighbors told people I am the community leader and to talk to the police. But how dare you! You are putting me in danger. I just want to get the trash to be gone and the rats. I need some help." (African American female resident - focus group 2)

The above examples of viewing police procedures as ineffective and not calling the police or intervening is consistent with the literature (Tyler, 2005). Several residents spoke about an increase in police presence due to a series of shootings in the neighborhood. "Now we see more foot patrols, they should have being doing that way before they started these shootings. Now they do it though." Residents were confident that the increase of police presence would soon dissolve after a period of calm (i.e., no more shootings).

Residents generally spoke about the desire for more quality community-based policing. One resident discussed the need for not only more police, but police who are invested and engaged in the community.

"There is a sustained presence now. When things happens they come, but these hotspots move. We need consistency in training because I have had bad and good police experiences. They talk to you with their hand on the gun. I went on a "cop walk" on a hot spot but only 3 or 4 people that are consistency there but if there is a concentration why can't we get more police officers. Other communities pay more taxes for more police, but should our safety depend on our ability to pay taxes and more taxes? We need community policing, we need more than 3 or 4 police officers who are invested. They should know my name and I should know their name." (African American female resident - focus group 1)

Residents believe police have negative perceptions of the neighborhood and people living there. Residents who have experienced disrespect or harassment by officers described the humiliation and frustration that follows. Police were also described as being "guarded" when interacting with residents. Several residents identified the high police turnover in the neighborhood as part of the reason residents are unable to develop meaningful relationships with officers. The frequent influx of new police officers does not allow time for officers and residents to develop rapport. Residents expressed a desire for more community police officers who walk the beat and get to know people in the neighborhood.

\section{Neighborhood Change and Lack of Cohesion}

Longtime residents often talked about the past and how the neighborhood has changed for the worst. They talked about the breakdown of the family, increase in crime, poor 
criminal justice response, and the decline of resident morals and values. They described how residents retreat to their homes to avoid neighborhood conflict. Residents described a neighborhood with poor communication.

"I think a stable with me was the elderly people who you looked up to when your parents weren't home. Now days, young people don't respect the elderly like they did. I think those were the folks that made sure you felt safe and followed the rules set by the community. It was your neighbors who didn't let you throw the trash or skip school, they didn't fear telling you or your parents. When I moved here, people thought it was strange when I knocked on the doors and told them about myself: I have a husband and two children and a cat. I come from an era where we did that. I tried to make those connections. It did take time for people to get used to that but it is amazing how disconnected we have become even in our communities and that breeds this notion that "these kids are not my kids," mentality." (African American female stakeholder - focus group 7)

"Everyone is defending by themselves, it used to be that if one parent was outside, they would watch over the other kids. People would volunteer to be responsible. So for us, to get that back, I would say have more community meetings, have more block parties, have fun activities for the kids while the parents have the meeting or just have parents volunteer to watch the kids. If people communicated better it would be a solution." (Young African American male - focus group 4)

The recognition that collective action is necessary to change neighborhood problems emerged when discussing the physical conditions of the area.

"It's a transient community, where people aren't going to invest because they are going leave anyway. In my area, people don't know people that are further north, but I think as properties are changing, where houses are changing, there are many neighborhoods but only like 2 groups but they are not working together even though they have the same interests. My neighbors have tried to work with the other community and the government but they don't get anywhere. So I think there needs to be some, just a bringing together, bringing a solidarity of issues, a movement. I have owned my property for 8 years but people have moved out because they don't have a great deal of success of yielding results. People are just concerned with their particular area instead of just a broader issues that covers lots of areas. We need people to be more interested in broader interests." (African American female resident - focus group 1)

A young resident who lived in the neighborhood as a child, left for several years, and returned described the change in area.

"I lived around here years ago, people had block parties; teenagers would be able to come together and teenagers didn't have problems with people coming over to other streets when I was a kid, but that doesn't happen anymore. It's more so, "you can't come on my block." The area changed, it seems new now, new 
dangers. A lot of [positive] activity stopped happening, lots of activities at the library for kids, I don't see block parties at all, usually the mayor would come around to block parties, talk to the kids give the kids school stuff." (Young African American male - focus group 4)

Lack of communication, avoidance of neighbors and local problems, transient residents, protection of individual interests, lack of local events to strengthen neighborhood relations contribute to the persistence of crime and disorder in the area. The absence of collective efficacy and trust prevents the community from rising above the negative conditions within. Residents are unlikely to take action, and work together, in a community where the rules are unclear and people mistrust one another (Sampson and Raudenbush, 1999). Research indicates that neighborhoods with high levels of collective efficacy have lower rates of disorder and crime. Sampson and Raudenbush's study (1999) found that collective efficacy predicted lower observed disorder after controlling for socio-demographics, land-use characteristics, perceived disorder, and prior rates of predatory crime. Research suggests not investing in formal policing strategies to prevent crime, and instead suggests developing informal but collective efforts among residents to reduce disorder and crime rates (Skogan and Hartnett, 1998; Sampson and Raudenbush, 1999).

\section{Limitations}

There are several limitations that should be discussed. The eight focus groups conducted may not represent all residents of the East Baltimore neighborhood. Recruitment of participants took many forms, however, participation was low in many of the groups. The main challenge was recruiting residents not active in neighborhood organizing or leadership roles. Getting non-"community-involved" participants to the table was challenging. Efforts to reach this population involved door-to-door flyers, flyers posted in local stores, and announcements at local events. The majority of residents who did show up for the focus groups were involved, or interested, in improving the neighborhood in some capacity. This limitation may be due to the voluntary nature of the focus groups, the lack of incentives provided, or the lack of trust in participating in a research activity. The sentiment about conducting research in the neighborhood was openly shared with the researchers during local meetings. Residents consistently explained that the neighborhood has been "over-researched" and the local conditions never change. This shared sentiment may explain the lack of participation by non- neighborhood involved residents.

Another limitation is the method used to collect data from residents. The use of focus groups to gather resident perceptions on neighborhood problems has several drawbacks. Residents may be untrusting of the group setting as a place to bring up serious neighborhood problems. To circumvent this issue the researchers administered a one-page survey to participants at the start of the focus group. Before the focus group discussion began residents were able to write down the top three problems in the neighborhood and potential solutions to these problems. During the focus group the written responses were discussed and collected at the end.

Additionally, the researchers were "outsiders" which may have also led to the inability to build rapport and trust amongst focus group members. To circumvent this 
issue the researchers began each group with a brief overview of the project, the importance of gathering information from residents, and the available funding to implement strategies based on identified problems. Researchers were honest with residents that they do not live in the neighborhood but were hired to collect the data to help identify problems and solutions. Focus group participants expressed great interest in discussing neighborhood problems and were pleased to know that funding already existed to address some of the core issues.

Regardless of these limitations, this study contributes to the literature on crime in disadvantage neighborhoods. By using qualitative techniques we were able to obtain a deeper understanding of the underlying community issues that contribute to crime. Gathering qualitative data on local neighborhood issues was specifically requested by stakeholders and community members. The interest in capturing resident perceptions stems from the long history of the neighborhood being "over-researched." We learned that there have been many survey research projects in the neighborhood that have not led to any identifiable change. Involving local residents in the process, and allowing their voices to contribute to improving the neighborhood, was a key priority of the BCJI grant. We strongly recommend that other researchers engaged in data collection activities designed to improve neighborhood conditions include the voice of those that live there.

\section{Discussion}

The themes identified from the focus groups are not unique to the East Baltimore neighborhood. They are problems identified in many urban neighborhoods with persistently high crime rates throughout the United States. Consistent with the literature on urban crime, four overarching themes illustrated throughout all focus groups is the need for collective action, long-term resident commitment, sustainable employment opportunities and recreational opportunities for youth. From the residents' perspective, without these components in place, crime and disorder will continue to flourish.

Economic resources for developing employment training and youth recreational opportunities is the first step in improving these two areas of need. Participants identified quality programs linked to positive outcomes and long-term sustainability of programs as barriers to effectively providing these services to residents. Residents in the neighborhood have had negative experiences with programs that are not linked to work, and with those that do not address the needs of people with criminal records. If an employment training program is to be funded in the neighborhood then it must be linked to job placement. Given the high prevalence of people with criminal records, employment programs must also not exclude this population. Expanding programs like the Baltimore STRIVE employment program would help provide opportunities to people returning from prison. STRIVE has been in operation in Baltimore since the late 1990s. This program provides job-readiness services, training and certificate programs, case management, and support services. A recent program evaluation indicated that sixty-two percent $(n=228)$ of participants were employed after completing the program. Seventy-five percent of those employed retained their job for at least six months (Abell Foundation, 2014). 
Youth programs also need to be expanded to reach more young people of all age (and gender) groups. These programs must also be tailored to fit the developmental needs, and life circumstances, of the youth they serve. Most importantly, youth programs should be led by local role models who understand the neighborhood context and life circumstances of young residents. For example, the Big Brother Big Sister Program is an effective program (Tierney et al., 2000), and one that currently operates in the City. Expanding it to reach more young people may fill this gap. Any youth program that provides mentoring and structured activity must include staff and mentees that can relate to the population. Lastly, residents need to see positive outcomes from the programs that are implemented in the neighborhood. Without visibility of programs "working" residents will remain discouraged.

A positive feature of the East Baltimore neighborhood is the high number of non-profit and faith-based organizations deeply invested in the improvement of the neighborhood. Sampson (2013) discussed the link between areas with high density non-profit organizations and high levels of collective efficacy. He argues that trust and shared expectations in the community setting is strengthened by the activities of organizations. The activities of local organizations bring residents together for common interests. The mere socialization that organizations generate can naturally enhance collective efficacy. Sampson argues that organizations also need strong interconnectedness among their leaders and activities to further enhance collective efficacy (Sampson, 2013).

As discussed in the focus groups, and at local meetings, residents believe that more neighborhood events that bring people out of their homes and into the neighborhood to interact is the first step towards building trust. Educating residents about the different resources and opportunities, and encouraging them to volunteer on neighborhood initiatives, are also important components. As part of the Byrne Grant funding, outreach workers in the neighborhood developed a quarterly newsletter to inform residents about local events and activities. The newsletter is delivered by a small team of outreach workers who physically go door-to-door to meet residents during the distribution. Residents of the neighborhood perceive this as an effective way to increase awareness of, and involvement in, neighborhood activities.

One of the major issues identified in the neighborhood was the high levels of physical disorder, and the poor relations with law enforcement. As identified by residents, improving the physical conditions will involve a neighborhood-wide approach. Residents also expressed the desire to have better quality policing - including community policing. Skogan (2006) describes a community-policing approach in Chicago that may be effective in the East Baltimore neighborhood. In Chicago efforts to address physical disorder involved applying a broken windows approach. This approach involved a range of non-punitive, collaborative efforts between police and the community. Police-community meetings were the central component in identifying top community problems and developing strategies to address the issues. Through this process Chicago developed interagency collaborations that brought together the police, community groups, and city services to the meetings to assist in addressing physical disorder and other problems. Some initiatives that were developed involved neighborhood cleanups, graffiti removal, fixing street lighting, neighborhood walks, and organized community events that involve the police. East Baltimore has strong community groups and a core team of invested leaders. Consistent and ongoing partnerships with the police and City agencies needs to be enhanced to truly address social and physical conditions. 
Identifying effective strategies and funding sources are two barriers preventing communities from improving neighborhood conditions. Fortunately, in this case, the Byrne Criminal Justice Grant requires grantees to use evidence-based programs and strategies to implement a crime prevention solution. The data gathered during the focus groups and other data collection efforts have been used to identify evidence-based practices and programs that have the potential to improve some of the core issues discovered. Community groups have been identified and funded to implement afterschool programs for youth, clean-up initiatives that involve hiring ex-offenders, job training and placement programs, and enhanced outreach and neighborhood event planning. Funding from the Byrne Grant has been allocated to implement these programs in 2014 and 2015. Once in place, these initiatives will be evaluated to assess the implementation process and program outcomes.

Acknowledgments This project was supported by Grant No. 2012-AJ-BX-0014 awarded by the Bureau of Justice Assistance. The Bureau of Justice Assistance is a component of the Office of Justice Programs, which also includes the Bureau of Justice Statistics, the National Institute of Justice, the Office of Juvenile Justice and Delinquency Prevention, the Office for Victims of Crime, and the Office of Sex Offender Sentencing, Monitoring, Apprehending, Registering and Tracking. Points of view or opinions in this document are those of the author and do not necessarily represent the official position or policies of the U.S. Department of Justice.

The authors would also like to acknowledge the BCJI grant project managers from the Baltimore City Mayor's Office on Criminal Justice, the members of the BCJI community-based steering committee, and the many community stakeholders and residents who participated in the data collection process.

\section{References}

Abell Foundation (2014). Case studies: STRIVE Baltimore. Baltimore: Abell Foundation Retrieved from http://www.abell.org/case-studies/strive-baltimore.

Brown, B., Perkins, D. D., \& Brown, G. (2003). Place attachment in a revitalizing neighborhood: Individual and block levels of analysis. Journal of Environmental Psychology, 23, 259-271.

Browning, C. R., Feinberg, S. L., \& Dietz, R. D. (2004). The paradox of social organization: Networks, collective efficacy, and violent crime in urban neighborhoods. Social Forces, 83(2), 503-534.

Carr, P. J., Napolitano, L., \& Keating, J. (2007). We never call the cops and here is why: A qualitative examination of legal cynicism in three Philadelphia neighborhoods. Criminology, 45(2), 445-480.

Chappell, A. T., Monk-Turner, E., \& Payne, B. K. (2011). Broken windows or window breakers: The influence of physical and social disorder on quality of life. Justice Quarterly, 28(3), 522-540.

Clear, T. R. (2007). Imprisoning communities: How mass incarceration makes disadvantaged neighborhoods worse. New York City: Oxford University Press.

Crutchfield, R. D., \& Pitchford, S. R. (1997). Work and crime: The effects of labor stratification on criminality. Social Forces, 76(1), 93-118.

Cullen, J. B., \& Levitt, S. D. (1999). Crime, urban flight, and the consequences for cities. The Review of Economics and Statistics, 81(2), 159-169.

Daily Beast. (2014). The Year in Murder: 2013 Marks a Historic Low for Many Cities. Retrieved on July 9 , 2014 from: http://www.thedailybeast.com/articles/2014/01/01/the-year-in-murder-2013-marks-a-historiclow-for-many-cities.html.

Holzer, H. J., Raphael, S., \& Stoll, M. (2004). Will employers hire ex-offenders? Employer preferences, background checks, and their determinants. In M. Patillo, D. F. Weiman, \& B. Western (Eds.), Imprisoning America: The social effects of mass incarceration (pp. 205-246). New York: Russell Sage Foundation.

Immergluck, D. (2012). Distressed and dumped: The market dynamics of low-value, foreclosed properties during the advent of the federal neighborhood stabilization program. Journal of Planning Education and Research, 32(1), 48-61. 
Katz, C. M., Webb, V. J., \& Schaefer, D. R. (2001). An assessment of the impact of quality-of-life policing on crime and disorder. Justice Quarterly, 18(4), 825-876.

Kelling, G. L., \& Sousa, W. H. (2001). Do police matter? An analysis of New York city's police reforms. New York: Manhattan Institute for Policy Research.

La Vigne, N. G., Kachnowski, V., Travis, J., Naser, R. L., \& Visher, C. (2003). A portrait of prisoner reentry in Maryland. Washington, DC: Urban Institute Justice Policy Center.

LaFrance, S., \& Twersky, F. (2001). A safe place for healthy youth development: A comprehensive evaluation of the bayview safe haven. San Francisco: BTW Consultants and LaFrance Associates Retrieved from http:// www.hfrp.org/out-of-school-time/ost-database-bibliography/database/bayview-safe-haven-program.

LeGates, R., Potepan, M., Blash, L., \& Gilbert, N. (1996). Literature review of urban and community development. San Francisco State University Public Research Institute, 1-67.

Lynch, J. P. \& Sabol, W. J. (2001). Prisoner reentry in perspective. Crime Policy Report (Vol. 3). Washington, DC: The Urban Institute.

Mahoney, J. L., Stattin, H., \& Magnusson, D. (2001). Youth recreation center participation and criminal offending: A 20-year longitudinal study of Swedish boys. International Journal of Behavioral Development, 25(6), 509-520.

Messner, S. F., Galea, S., Tardiff, K. J., Tracy, M., Bucciarelli, A., Piper, T. M, Frye, V., \& Vlahov, D. (2007). Policing, drugs, and the homicide decline in New York city in the 1990s. Criminology, 45(2), 385-414.

Nix, J., Wolfe, S. E., Rojek, J., \& Kaminski, R. J. (2015). Trust in the police: The influence of procedural justice and perceived collective efficacy. Crime and Delinquency, 61(4), 610-640.

Office of Juvenile Justice and Delinquency Prevention (2014). OJJDP statistical briefing book. Online.

Osgood, D. W., Anderson, A. L., \& Shaffer, J. N. (2005). Unstructured leisure in the after-school hours. In J. L. Mahoney, R. W. Larson, \& J. S. Eccles (Eds.), Organized activities as contexts of development. Mahwah: Lawrence Erlbaum Associates.

Pager, D. (2002). The mark of a criminal record. American Journal of Sociology, 108(5), 937-975.

Pattillo, M. E. (1998). Sweet mothers and gangbangers: Managing crime in a black middle-class neighborhood. Social Forces, 76(3), 747-774.

Petersillia, J. (2001). When prisoners return to the community: Political, economic and social consequences. Corrections Management Quarterly, 5(3), 1-10.

Peterson, R. D., Krivo, L. J., \& Harris, M. A. (2000). Disadvantage and neighborhood violent crime: Do local institutions matter? Journal of Research in Crime and Delinquency, 37, 31-63.

Pietila, A. (2010). Not in my neighborhood: How bigotry shaped a great American city. Chicago: Ivan R. Dee.

Pitner, R. O., Yu, M. S., \& Brown, E. (2012). Making neighborhoods safer: Examining predicators of residents' concerns about neighborhood safety. Journal of Environmental Psychology, 32, 43-49.

Ren, L., Cao, L., Lovrich, N., \& Gaffney, M. (2005). Linking confidence in the police with the performance of the police: Community policing can make a difference. Journal of Criminal Justice, 33, 55-66.

Rorie, M., Gottfredson, D. C., Cross, A., Wilson, D., \& Connell, N. M. (2011). Structure and deviancy training in after-school programs. Journal of Adolescence, 34(1), 105-117.

Sampson, R. J. (2012). Great American City: Chicago and the enduring neighborhood effect. Chicago, Il: The University of Chicago Press.

Sampson, R. J. (2013). 2012 presidential address to the American society of criminology. The place of context: A theory and strategy for criminology's hard problems. Criminology, 51(1), 1-31.

Sampson, R. J., \& Bartusch, D. J. (1998). Legal cynicism and (subcultural?) tolerance of deviance: The neighborhood context of racial differences. Law and Society Review, 32, 777-804.

Sampson, R. J., \& Laub, J. H. (1993). Crime in the making: Pathways and turning points through life. Cambridge: Harvard University Press.

Sampson, R. J., \& Raudenbush, S. W. (1999). Systematic social observation of public spaces: A new look at disorder in urban neighborhoods. American Journal of Sociology, 105(3), 603-651.

Sampson, R. J., \& Raudenbush, S. W. (2004). Seeing disorder: Neighborhood stigma and the social construction of "broken windows.". Social Psychology Quarterly, 67(4), 319-342.

Sampson, R. J., Raudenbush, S., \& Earls, F. (1997). Neighborhoods and violent crime: A multilevel study of collective efficacy. Science, 277, 918-924.

Sampson, R. J., Morenoff, J., \& Earls, F. (1999). Beyond social capital: Spatial dynamics of collective efficacy for children. American Sociological Review, 64(5), 633-660.

Seal, D., Nguyen, A., \& Beyer, K. (2014). Youth exposure to violence in an urban setting. Urban Studies Research. 1-11.

Shaw, C. R., \& McKay, H. D. (1931). Social factors in juvenile delinquency. Report on the causes of crime, National Commission of Law Observance and Enforcement, 2. Washington, DC: Government Printing Office.

Shaw, C. R., \& McKay, H. (1942). Juvenile delinquency and urban areas. Chicago: University of Chicago Press. 
Skogan, W. G. (1990). Disorder and decline: Crime and the spiral of decay in American neighborhoods. Los Angeles: University of California Press.

Skogan, W. G. (2006). Police and community in Chicago. New York: Oxford University Press.

Skogan, W., \& Hartnett, S. (1998). Community policing, Chicago style. New York: Oxford University Press.

Solomon, A., Roman, C. G., \& Waul, M. (2001). Summary of focus group with Ex-prisoners in the district: Ingredients for successful reintegration. Washington, DC: The Urban Institute.

Spelman, W. (1993). Abandoned buildings: Magnets for crime? Journal of Criminal Justice, 21, 481-495.

Taylor, R. B. (1999). Crime, fear, and decline: A longitudinal look. Research brief. Washington, DC:. Department of Justice, National Institute of Justice.

Tierney, J. P., Baldwin Grossman, J., \& Resch, N. L. (2000). Making a difference: An impact study of Big brothers/Big sisters. Philadelphia: Public/Private Ventures.

Tyler, T. R. (2005). Policing in black and white: Ethic group differences in trust and confidence in the police. Police Quarterly, 8, 322-342.

Uggen, C. (1999). Ex-offenders and the conformist alternative: A job quality model of work and crime. Social Problems, 46(1), 127-151.

Van Arnum, B. (2014). Recreation Center Closings in Baltimore: Reconsidering Spending Priorities, Juvenile Crime, and Equity. Baltimore, MD: Citizens Planning and Housing Association. http://www.cphabaltimore. org/wp-content/uploads/2014/09/Recreation-Center-White-Paper-as-of-2.3.141.pdf.

Visher, C., \& Travis, J. (2003). Transitions from prison to community: Understanding individual pathways. Annual Review of Sociology, 29, 89-113.

Visher, C. A., Debus-Sherrill, S. A., \& Yahner, J. (2011). Employment after prison: A longitudinal study of former prisoners. Justice Quarterly, 28(5), 698-718.

Webster, D. W., Mendel Whitehill, M., Vernick, J. S., \& Parker, Elizabeth, M. (2012). Evaluation of Baltimore's safe streets program: Effects on attitudes, participants' experiences, and Gun violence. John Hopkins Center for Prevention of Youth Violence, John Hopkins Bloomberg School of Public Health.

Wenger, Y. (2013). City closes about 20 rec centers; private groups fill gap. July 2, 2013. Baltimore: Baltimore Sun.

Western, B., Kling, J. R., \& Weiman, D. (2001). The labor market consequences of incarceration. Crime and Delinquency, 47, 410-427.

Wilson, W. J. (1987). The truly disadvantaged: the inner city, the underclass and public policy. Chicago: University of Chicago Press.

Wilson, W. J. (1996). When work disappears: The world of the new urban poor. New York: Vintage Books, Random House.

Wilson, J. Q., \& Kelling, G. (1982). The police and neighborhood safety: Broken windows. The Atlantic Monthly, 127, 29-38.

Dr. Andrea Cantora is an Assistant Professor in the School of Criminal Justice at the University of Baltimore. She received her doctorate in Criminal Justice from The City University of New York City/John Jay College of Criminal Justice. Dr. Cantora's research focus is on correctional policy and programming, prisoner reentry, and urban crime prevention. Her work has been published in the Journal of Offender Rehabilitation, the Journal of Qualitative Criminal Justice and Criminology, and Criminal Justice Studies.

Dr. Seema D. Iyer is Associate Director of the Jacob France Institute at the University of Baltimore. She oversee the Baltimore Neighborhood Indicators Alliance which acquires, integrates and disseminates quality of life data. She served as Research Division Chief of the Baltimore City Planning Department from 20052011. Dr. Iyer's PhD is in Urban and Regional Planning from the University of Michigan, Ann Arbor. Her research focus is on how community-based indicators help explain structural contexts of policy and the impact of data sharing in collaborative innovation processes. She has published in International Planning Studies and collaborated in several edited book volumes.

Lauren Restivo is a recent graduate of the University of Baltimore, School Criminal Justice Master's Program. Lauren has worked on multiple research projects while obtaining her Master's degree. She earned her BA in criminology from the University of Maryland in 2011. Lauren's research interest includes intimate partner violence, corrections, and the intersection of mental health and criminal justice. 
Reproduced with permission of the copyright owner. Further reproduction prohibited without permission. 